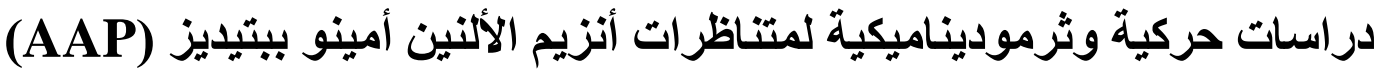

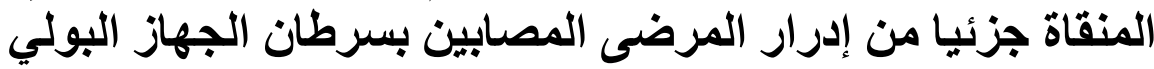

\author{
تغريا علوم العقبي" \\ استلام البحث 3،شباط ، 2013 \\ قبول النشر 8، أيلول، 2013 ( 2013
}

تم في دراسة سابقة قياس نشاط أنزيم الالنين امينو بيتيديز ( AAP ) في إنياء إدرار المرضى المصابين بسرطان

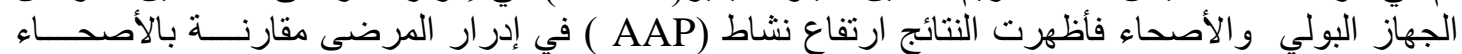

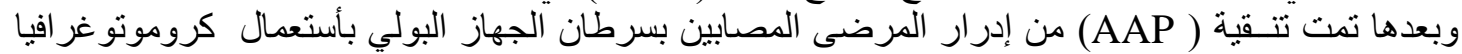

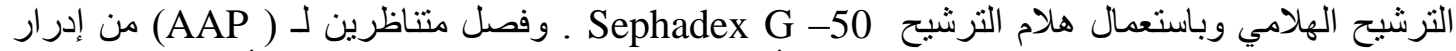

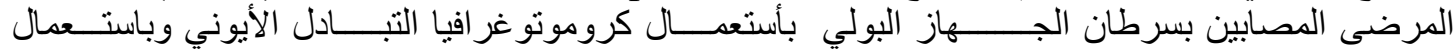

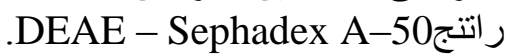

تضمن البحث الحالي دراسة الصفات الحركية والثرموديناميكية لمتناظري أنزيم الالنين امينوبيتبديز II,I المنقاة

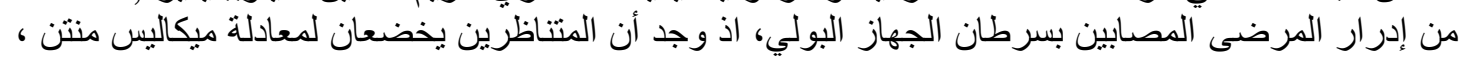

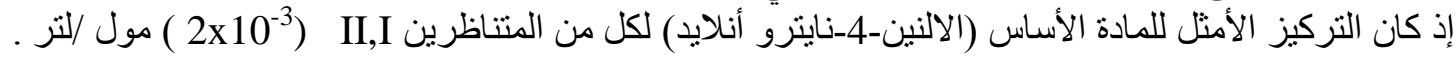

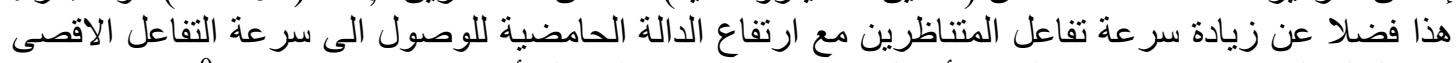

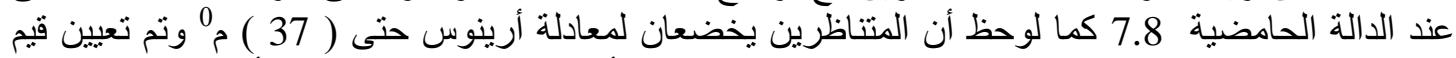

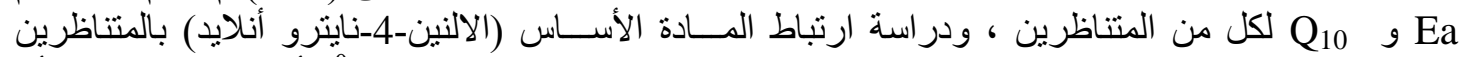

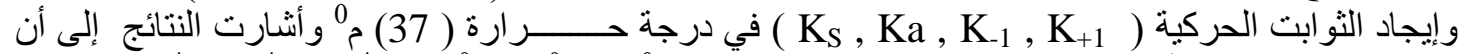
التفاعل من المرتبة الأولى ـ وحساب الدو ال الثرموديناميكية) لنشاط أنزيم الالنين أمينوبيتيديز (AAP) من خلال معادلتي فانت هوف وأرينوس للحالتين القياسية والانتقالية .

الكلمات المفتاحية : أنزيم الالنين أمينوبيتيديز ، سرطان الجهاز البولي .

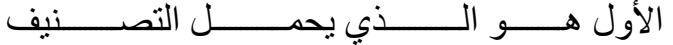
(EC3.4.11.1) وله تخصص تجاه المادة الاساس الناس

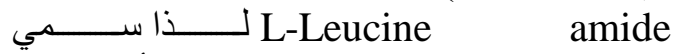
أمسـ Leucineaminopeptidase(LAP) الآخرفهـ (EC 3.4.11.2) Microsomal) الذي

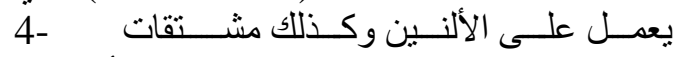
م-Naphthylamide Nitroanilide

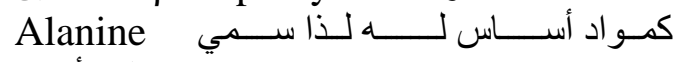
[5].aminopeptidase(AAP)

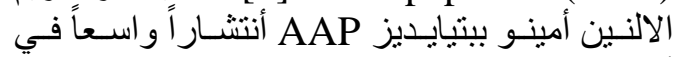

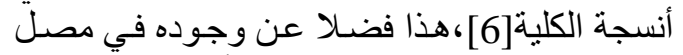

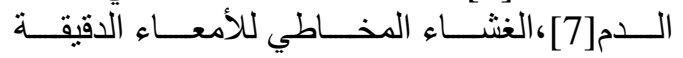

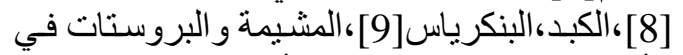

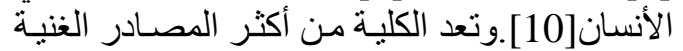

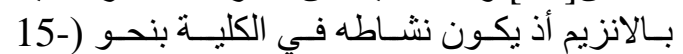

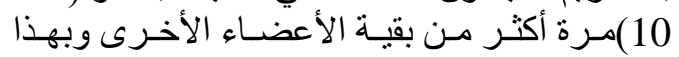

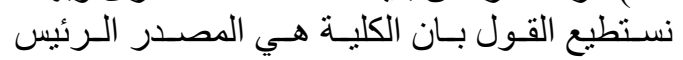

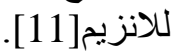

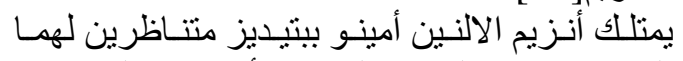
الوظيفة نفسها ولكن يختلفان في أوز انهما الجزيئية الجية،

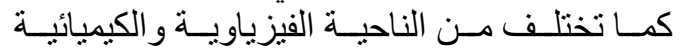

المقدمة:

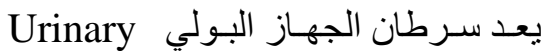
مصطلحا عامـا لأور ام ام الحان (tract cancer U.T.C)

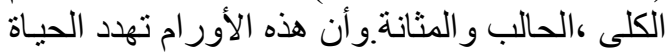

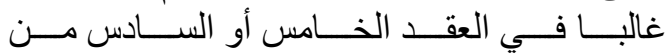

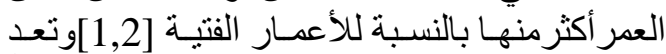

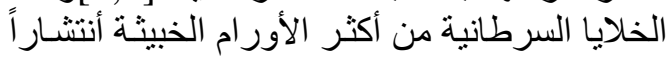

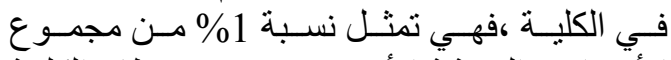

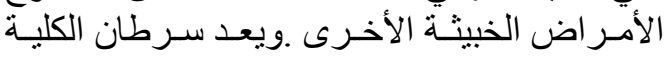

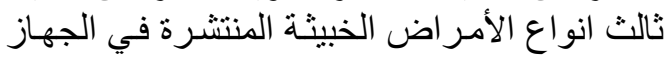

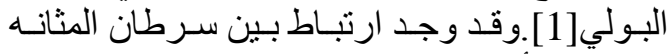

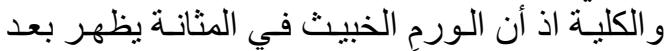

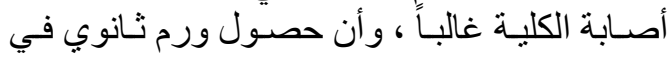

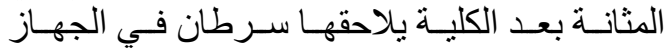

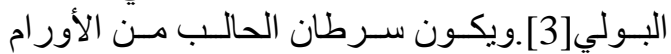

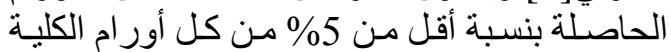

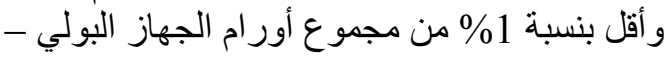
ينتمي أنزيم الألنين أمينو بينايديز AAP الـى

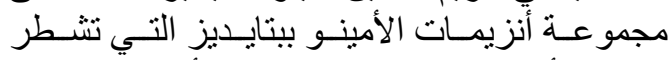

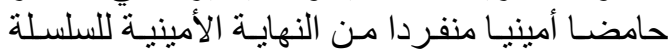

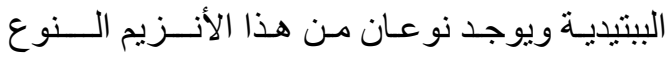

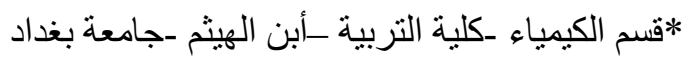


hydrochloride وذللك بعد مقارنـة الأمتصاصية للعينة بـالمنحني القياسي لتر اكيز مختلفة من المـادة

.[12] 4-Nitroanilide 2- دراسـة الصـفات الحركيـة لمتنـاظرات الألنين

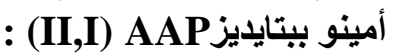

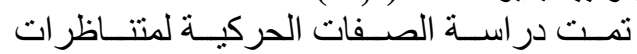

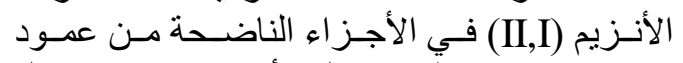

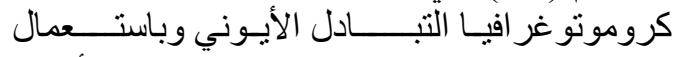

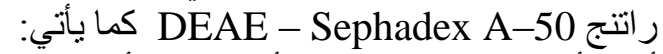

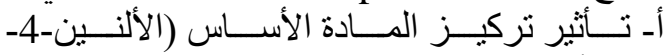
نايترو أنلابيد): درس تـأثير التر اكيـز المختلفـة للمـادة الأســاس

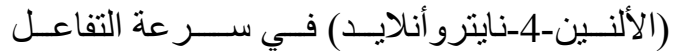

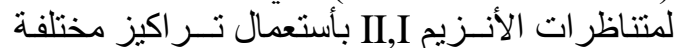

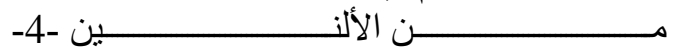

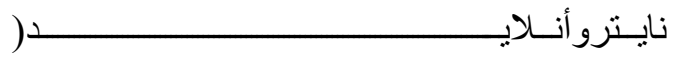

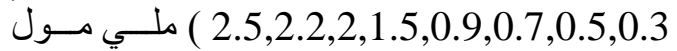
II,I لترلحساب التركيز الامثل لمتناظرات الانزيم

بـ تعيين قيم ثابت ميكاليس-منتن(Km):

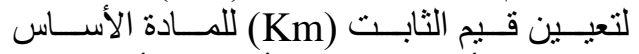

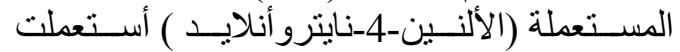

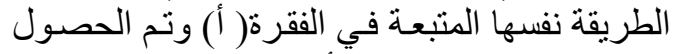

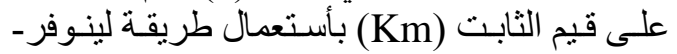

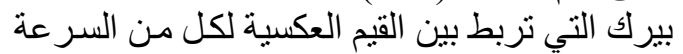

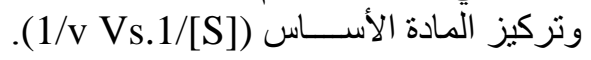

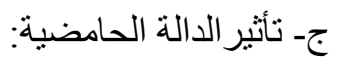

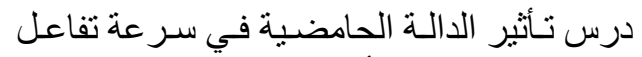
المتنـاظر ات II,I إذ تـم أستعمال قيم مختلفــة للادالـة

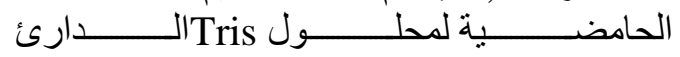

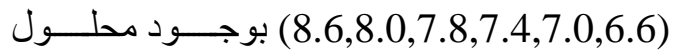
المادة الأساس بتركيز (2) ملي مول/لتر ونم التفاعل

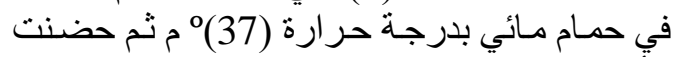

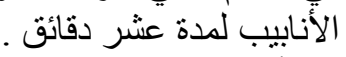

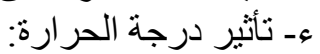

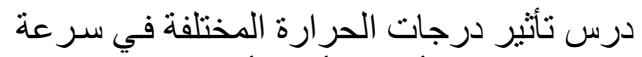

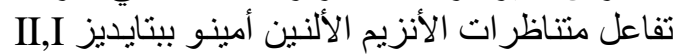

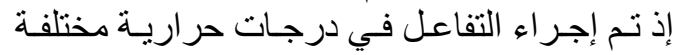

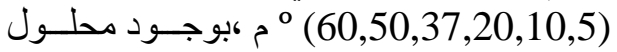
الأدارئ ذي الدالـة الحامضية(7.8 (7.8) ،و التركيز

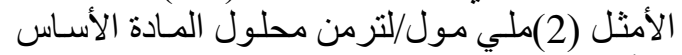
(الألنين-4-نايترو انلايد).

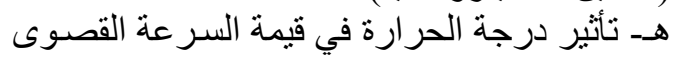

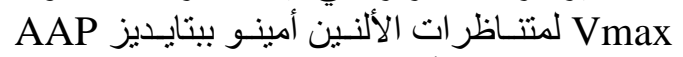

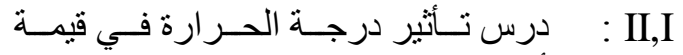

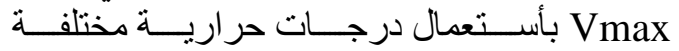
(60,50,37,20,10,5)

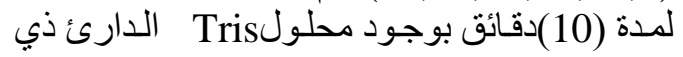

و الحركيـة ، وتـم فصـل وتنقيـة متتــاظر ات الانـزيم

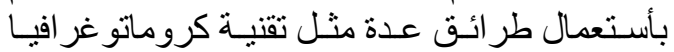

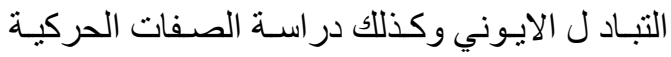

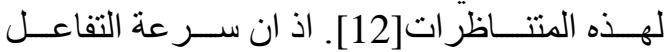

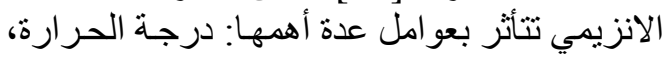

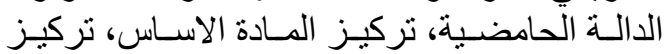

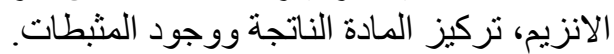

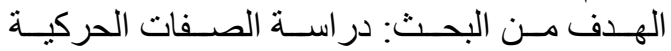

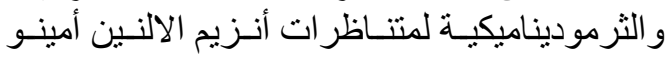

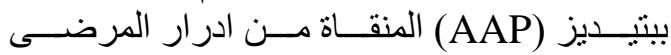

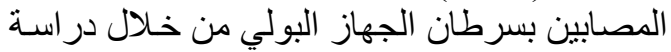

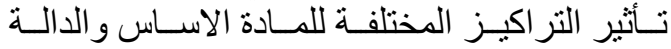
الحامضية ودرجة الحر ارة في فعالية الانزيم.

\section{المواد وطر ائق العمل : جمع العينـات:}

تمع جمع (36) عينة التهنة إدرار من الأشخاص

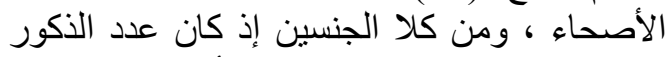

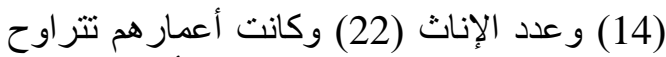

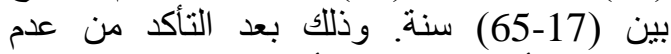
إصابتهم بأي مرض من من أمراض اضلف الجهاز البولي. وقد نم في دراسة سابقة قياس نشاط أنزيم الالنين

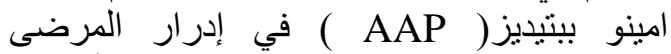

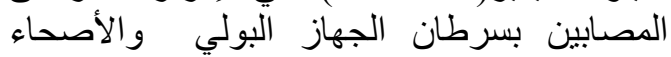
فأظهرت النتائج ارتفاع نشاط (AAP) في إدراء الار

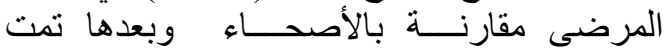

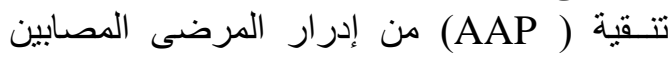

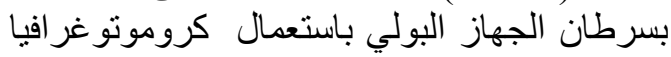

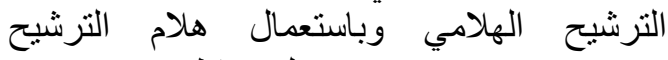

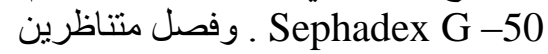
لـ (AAP) من إدرار المرضى المصابين بسرطان

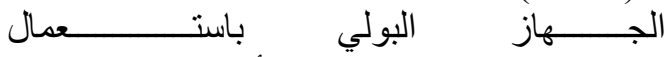

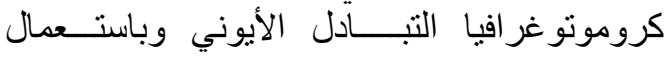

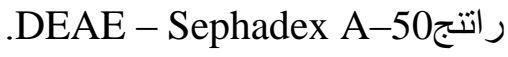

(U. T. C) أما النماذج المرضية للمصابين بـ (34)

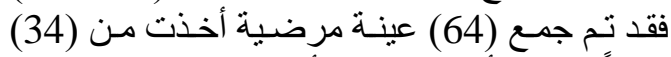
ذكر اً و(30) أنثى تتر اوح أعمار هم بين (18-74)

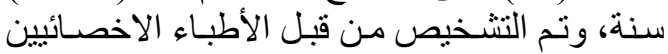

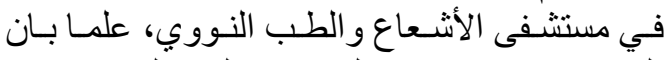

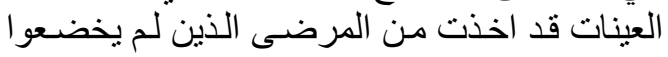

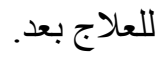

1- قياس فعالية أنزيم الألنين أمينو ببتايديز AAP في الأدرار:

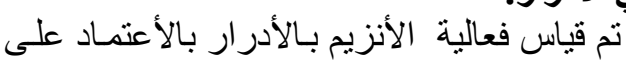

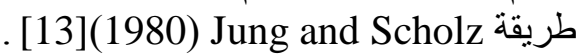

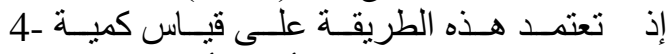
Nitroanilide الأسـاس المستعملة Alanine-4-nitroanilide 
المرضى المصابين بسرطان الجهاز البولي وهذا

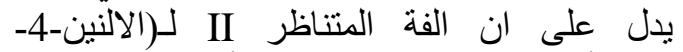
نايترو أنلايد)في ادرار الاصحاء أقل من الفته في لإني ادرار المرضى المصابين بسرطان الجهاز البولي.

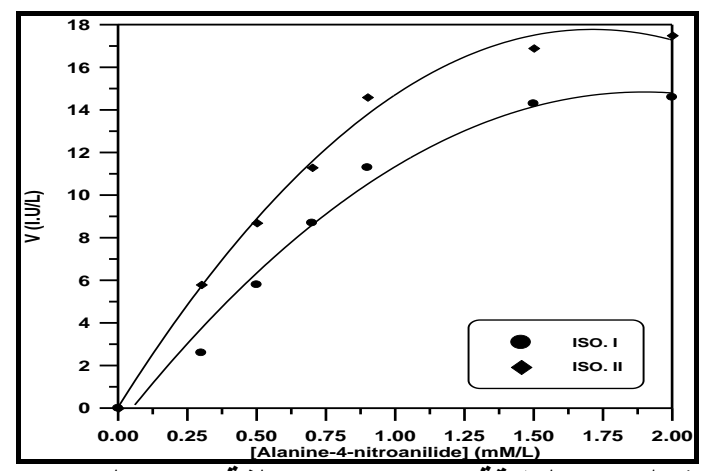

شكل (1):العلاقة بين تراكيز مختلفة من (الالنين -

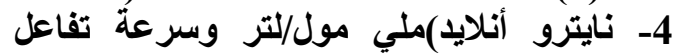

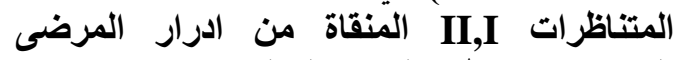
المصابين بسرطان الجهاز البولي.
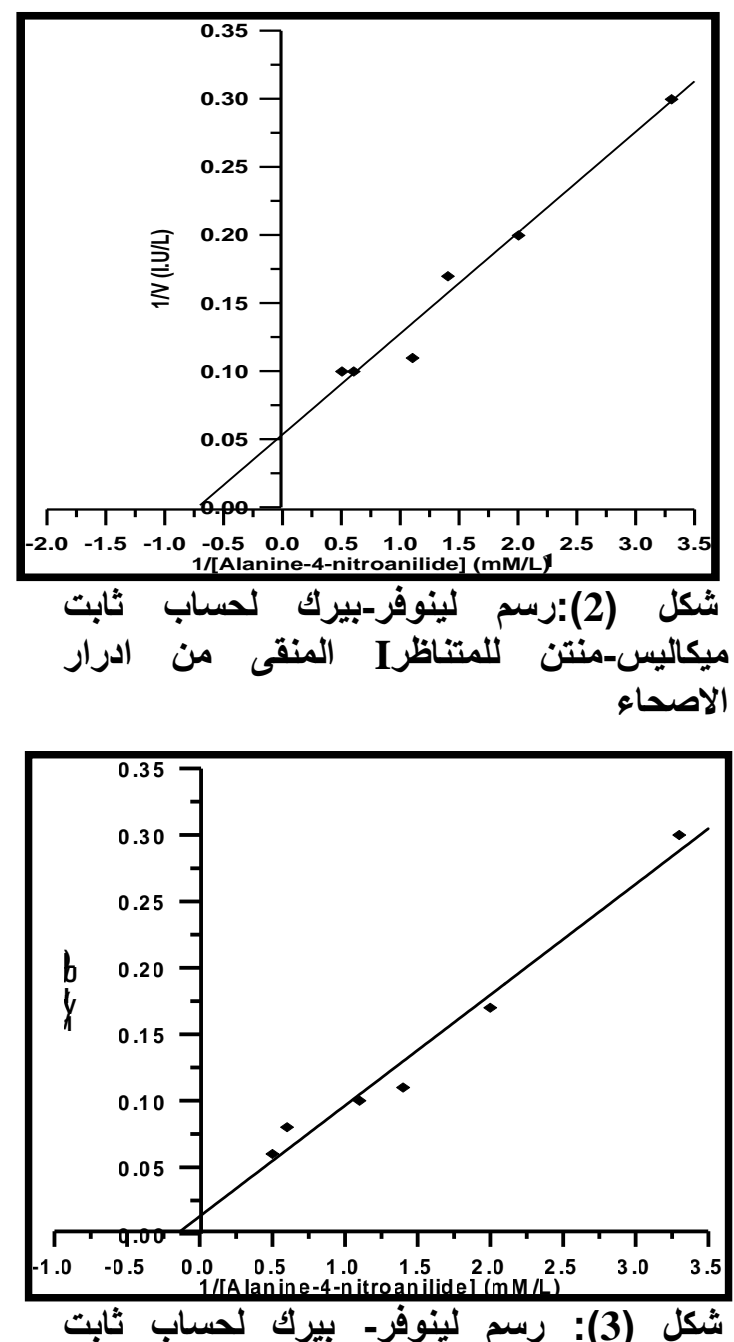

ميكاليس - منتن للمتنـاظر II المنقى من إد رار الأصحاء.
الدالة|الحامضية(7.8) و أستعمال تر اكيز مختلفة من

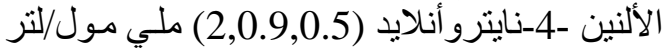
وبالأعنماد على المعادلات الأتثية:

Slope $=-\mathrm{Ea} / 2.303$

$\mathrm{Ea}=2.303 \mathrm{R}(\mathrm{T} 2 . \mathrm{T} 1) \log \mathrm{Q} 10 / 10$

\section{النتائج و المناقشة:}

1- تعيين قيم ثابت ميكاليس - منتن ( Km ) :

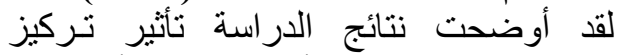

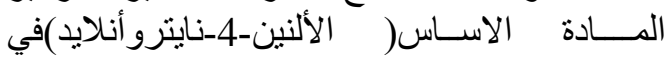
سر عة التفاعل الأنزيمي للمتناظرين II,I مع أرتفاع الأنين

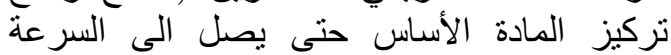

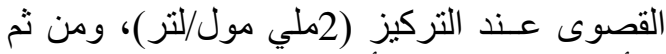

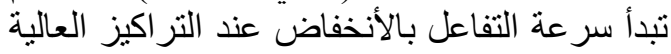
من المادة الأساس نتيجة لحدوث بلأنفاض التثبيط كما موضح التحالية في الثكل رقم(1).

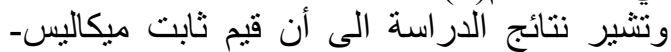
منتنKm النتي تم حسابها بالأعتماد على معابت معادلة لينوفر-بيرك

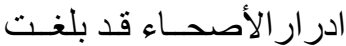

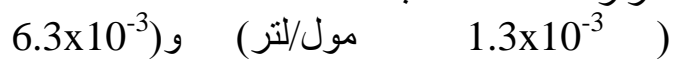

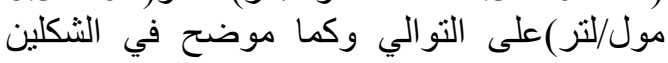

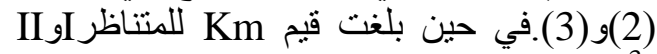

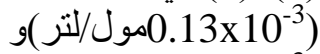
ماتومل

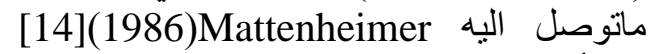

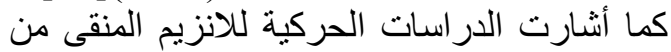

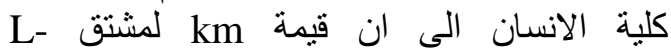
methionyl-beta naphythylamide تكون و اطئة اذ بلغت . [15] $\left(1.4 \times 10^{-5}\right)$

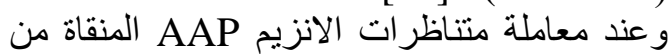
بنكرياس، كلية وكبد الانسان بالاجسام المضادئ الادئ

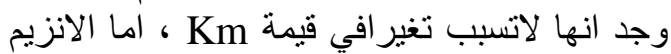

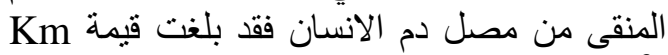

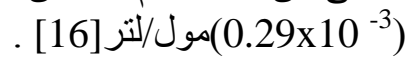
اما في ادرار المرضى المكسابين بسرطان الجهاز

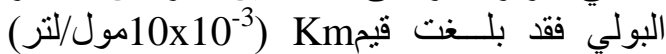

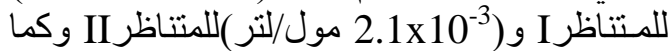

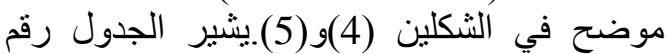

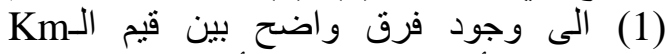

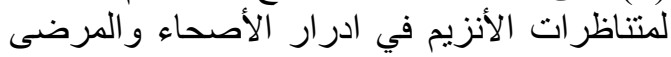

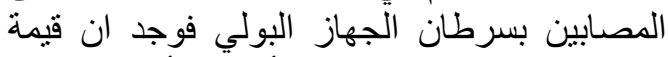

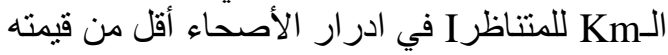

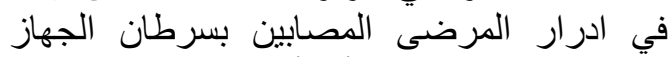

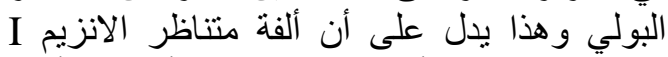

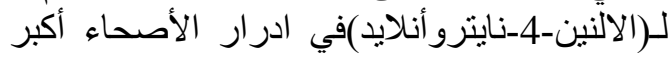

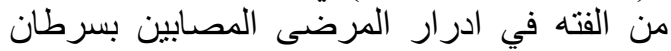

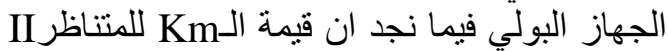
في ادرار الاصحاء أكبر من قيمته في ادرار 
الثكلين (6)و(7). كما اظهر الانزيم الهنقى من ون

انسجة ثدي ومصل دم الانسان دالة حامضية مثلى النى

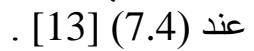

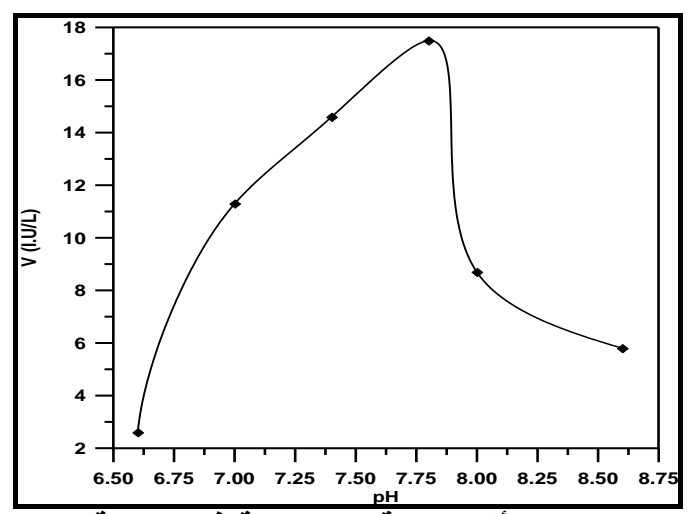

شكل (6) : تأثير الدالة الحامضية في سرعة تفاعل

المتناظر I

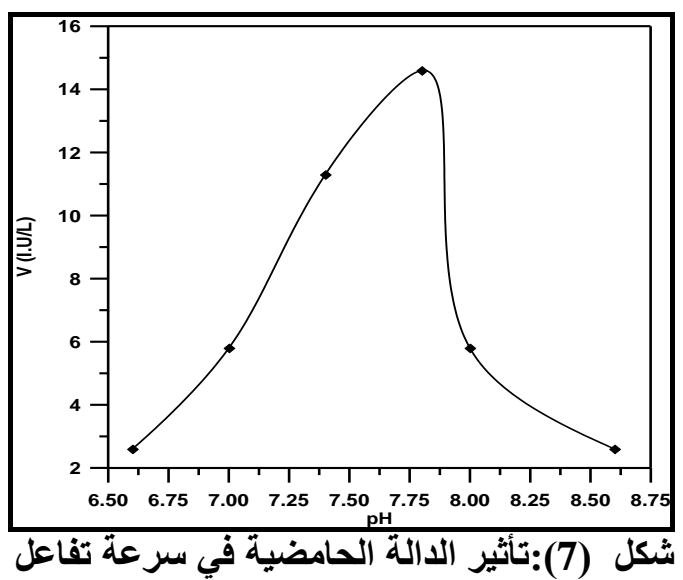

المتناظر II (7)

كذلك أظهرت نتائج الدراسة تأثير درجة الحرارة

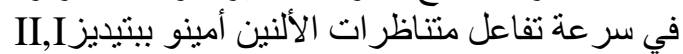

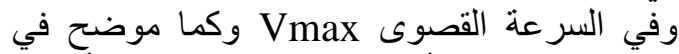

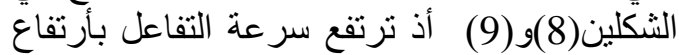

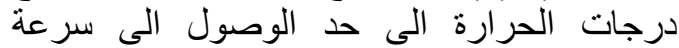

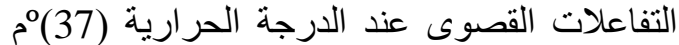
ومن ثم تبدأ سرعة التفاعل بالأنخفاض. كما وجدار

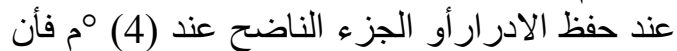
الانزيم يحافظ على نشاطه خلال ستخة أيام، أما عند الندان

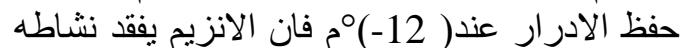

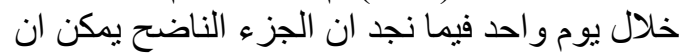

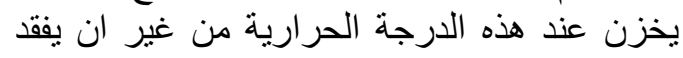

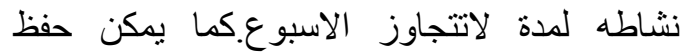

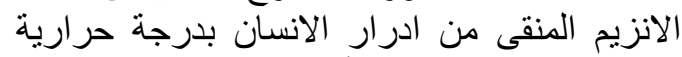

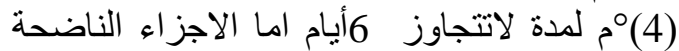

فتكون مستقرة عند(20-) مج لمدة اسبو عين [13].
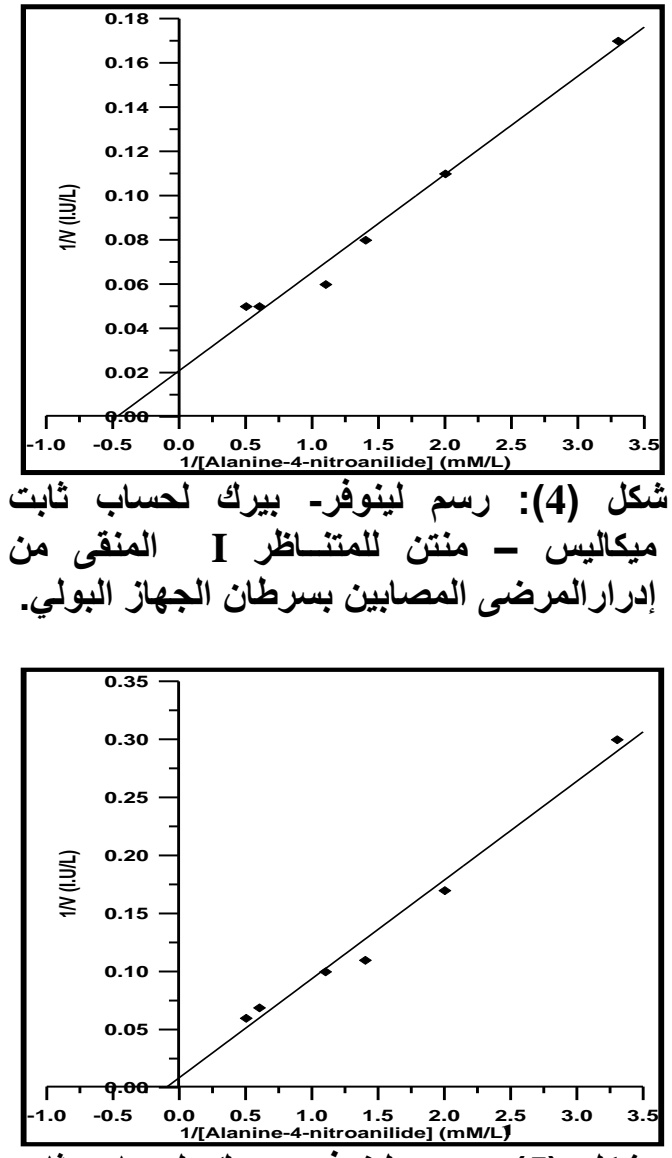

شكل (5): رسم لينوفر- بيرك لحساب ثابت

ميكاليس - منتن للمتناظر البنال المنقى من إدرار المرضى المصابين بسرطان الجهاز البولي.

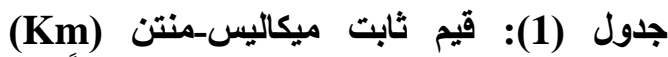

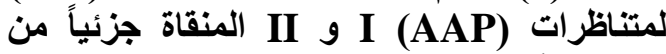

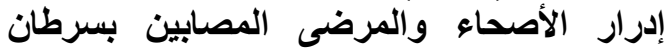
الجهاز البولي بالاعتماد على معادلة لينوفربيرك

\begin{tabular}{|r|r|r|r|}
\hline \multirow{2}{*}{ Enzyme } & \multirow{2}{*}{ Substrate } & \multicolumn{2}{|c|}{ Km(mol/liter) } \\
\cline { 3 - 4 } & & \multicolumn{2}{|c|}{$1 / \mathrm{V}$ Vs.1/[S] } \\
\cline { 3 - 4 } & & Normal & U.T.C \\
\hline $\begin{array}{r}\text { Isoenzym } \\
\text { e I }\end{array}$ & $\begin{array}{r}\text { Alanine -4- } \\
\text { nitroanilide }\end{array}$ & $1.3 \times 10^{-3}$ & $\begin{array}{r}10 \times 10^{-} \\
3\end{array}$ \\
\hline $\begin{array}{r}\text { Isoenzym } \\
\text { e II }\end{array}$ & $\begin{array}{r}\text { Alanine -4- } \\
\text { nitroanilide }\end{array}$ & $6.3 \times 10^{-3}$ & $\begin{array}{r}2.1 \times 10 \\
-3\end{array}$ \\
\hline
\end{tabular}

كما أوضحت نتائج الدراسة حدوث ارتفاع في

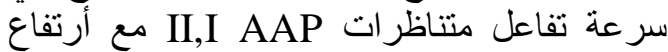

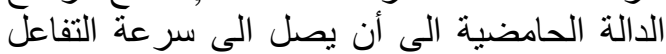

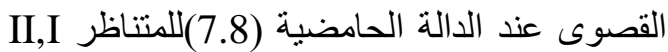

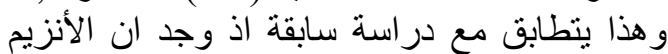

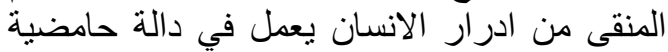
تترواح (7.4-8.0)في حين ان الألدالة الحامضية

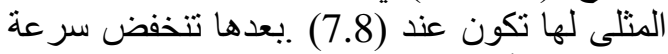

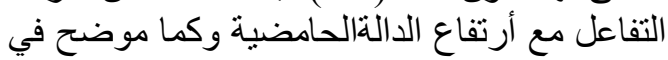


T: درجة الحر ارة المطلقة(كلفن)

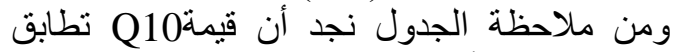

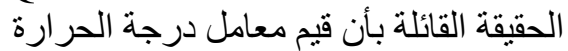

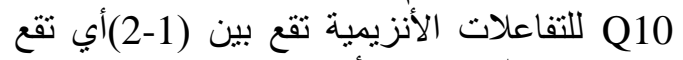
ضمن مدى التفاعلات الأنزيمية [18].

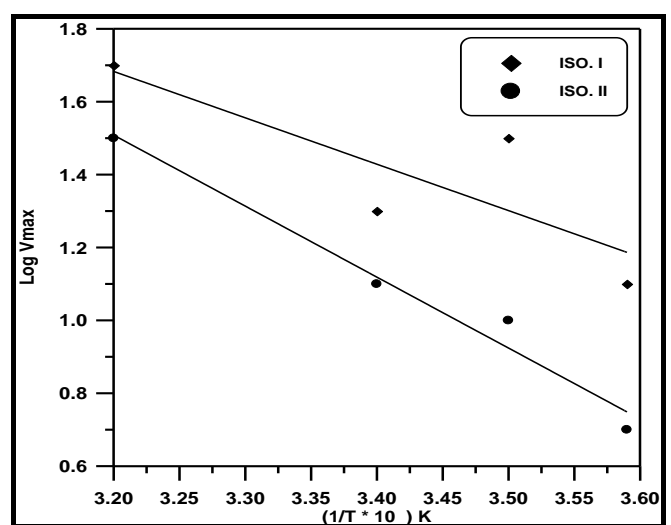
شكل (10):رسم لعلاقة أرينوس بين تأثير مقلوب

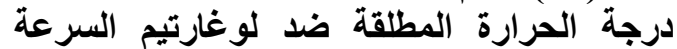

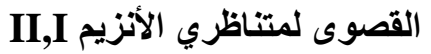

جدول (2): قيم (EA) و (Q10) لمتناظرات II و I (AAP)

\begin{tabular}{|c|c|c|}
\hline Enzymes & $\mathrm{E}_{\mathrm{a}}(\mathrm{Cal})$ & $\mathrm{Q}_{10}$ \\
\hline Isoenzyme I & 30087 & 1.0004 \\
\hline Isoenzyme II & 38294 & 1.0005 \\
\hline
\end{tabular}

2- الاراسات الثرموديناميكية لأرتباط المادة الأساس بمتناظرات أنزيم الالنين امينوينية لارتباطينيز 1.المعاملات الثرموديناميكية للحالة القياسية : II,I (AAP)

كم كساب قيم الدوال الثرمودينامكية (AS) ( من المعادلات الأتية: اذ نم حساب قيمة طاقة جبس الحرة ( المعادلة : الن $\Delta \mathrm{G}^{\mathrm{o}}=-\mathrm{RT} \ln \mathrm{Ka}$ ( 5 ) اذ ان : (5) Ka

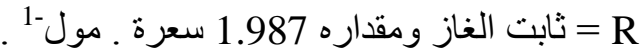
كلفن-1و = T

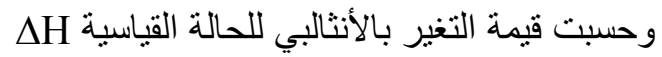
من معادلة فانت هوف ( Vant Hoffs ) كما بالنير

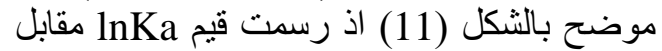

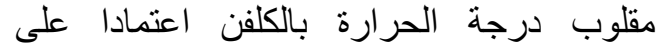
المعادلة

$\operatorname{lnKa}=-\Delta \mathrm{H} \quad / \mathrm{RT}+\mathrm{C}$
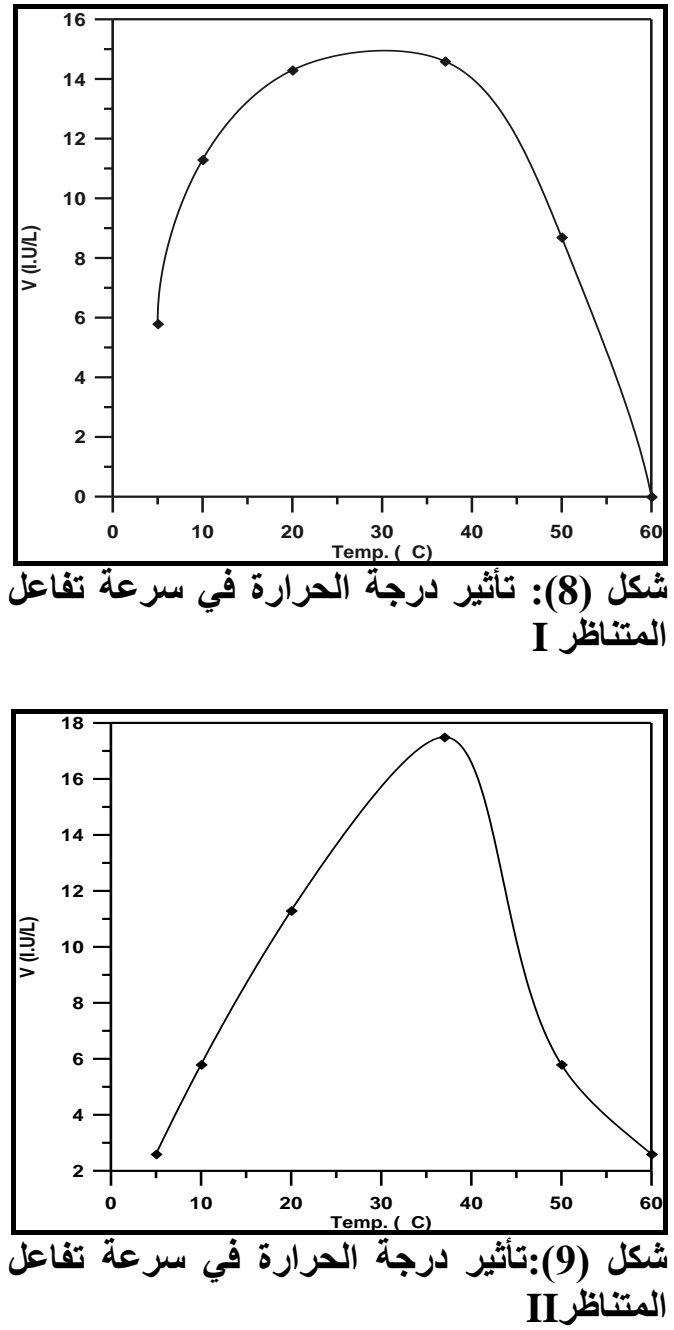

أما الثكل رقم (10) فيوضح العلاقة بين لو غارينم

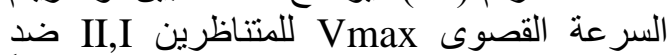
مقلوب درجة الحرارة المطلقة التي تعطي خطاً مستقيماً والتي تتبع معادلة أرينوس الآتية[117]: $\ln \mathrm{k}=-\mathrm{Ea} / \mathrm{RT}+$ constant وقد أظهرت النتائج بأن كلا المتناظرين II,I

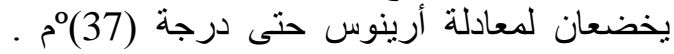
كماتم حساب الطاقة المنشطة للتفاعل Ea وذلئل

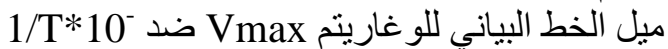
3 و المتمثل بالمعادلة الآتية: $\log \mathrm{k}=-\mathrm{Ea} / 2.3 \mathrm{R} * 1 / \mathrm{T}+\log \mathrm{A}$ لذا فأن ميل الخط البياني = Ea/2.3R ويوضح الجدول رقم(2) قيم الطاقة المنشطة Ea وقيم Q10 للمتناظرين II,I وتم تعيين Q10 من الأنة خلال المعادلة الآتية:

$\mathrm{Ea}=2.3 \mathrm{RT} 2 * \mathrm{~T} 1 \log \mathrm{Q} 10 / 10$

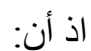

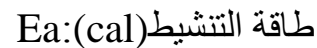
Q معامل درجة الحرارة:Q10 R:الثنابت العام للغاز ات(1.987) 


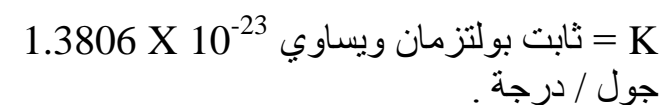
تثابت بلانك ويعادل 6.626 x $10^{-34}$ جول . ثانية . تابة ويمكن حساب التغير في الأنتروبي للحالة الانتقالية : من المعادلة ( $\Delta \mathrm{S}^{*}=\left(\Delta \mathrm{H}^{*}-\Delta^{*}\right) / \mathrm{T}$ ( 12 )

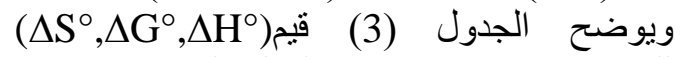
للمتناظرين (II I I ) في الحالة القياسية وبدرجة

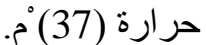

ومن ملاحظة القيم المذكورة في الجدول

رقم(3) نجد قيمة

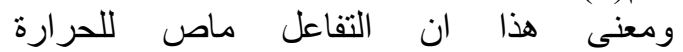
هG

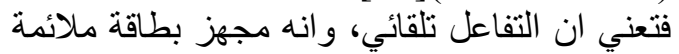

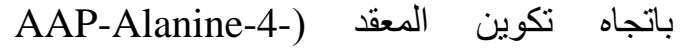
. nitroanilide كما ان القيمة الموجبة للتغير في الانثالبي القياسي من الممكن ان تعود إلى التفاعلات الميلائمة التئية

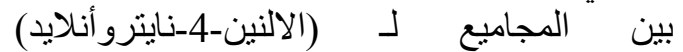

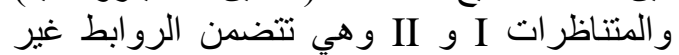
تساهمية التي تكون الكتروستاتيكية في طبينة التيعتها

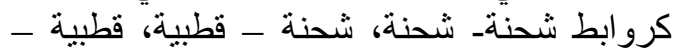
قطبية واواصر هايدروجينية.وتساعد هذه الروابط

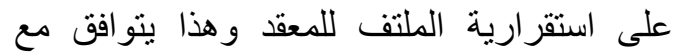
القيمة الموجبة في الانثالبي القياسي[20]

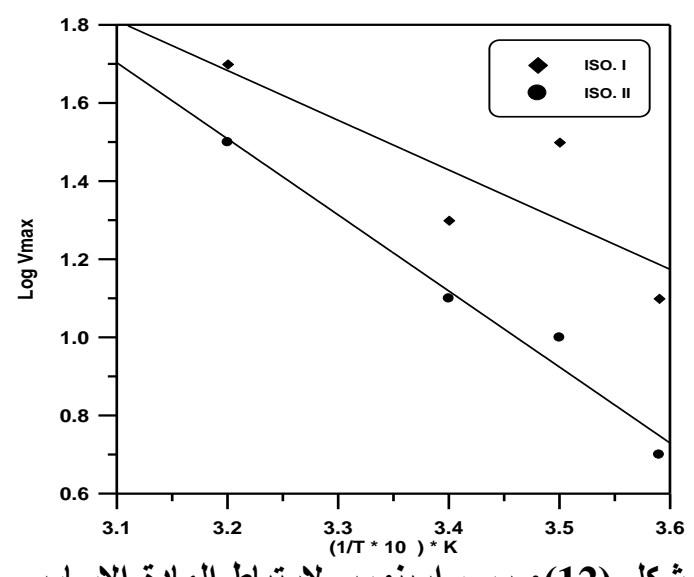

شكل (12): رسم ارينوس لارتباط المادة الاساس

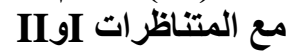

اذ أن : دH = التغير بالأنثالبي .

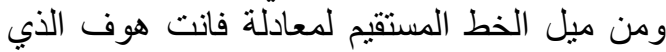

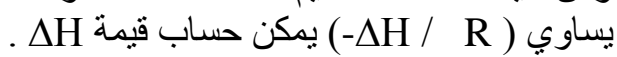

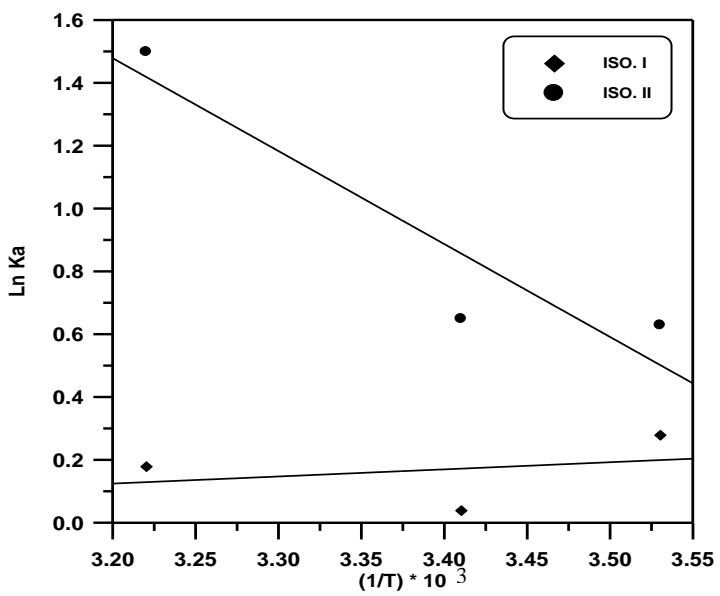

شكل (11): رسم فاتت هوف لارتباط المادة

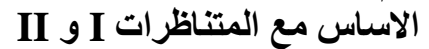

أما SS فتحسب من المعادلة الآتية : $\Delta \mathrm{S}^{0}=\left(\Delta \mathrm{H}^{\circ}-\Delta \mathrm{G}^{0}\right) / \mathrm{T}$

2.المعاملات الثرموديناميكية للحالة الانتقالية

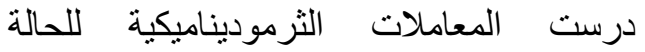
الانتقالية باستعمال المعادلات الآتية [19] :

$\Delta \mathrm{H}^{*}=\mathrm{Ea}-\mathrm{RT}$

$\log \mathrm{V}_{\max }=\log \mathrm{A}-\mathrm{Ea} / 2.303 \mathrm{RT}$

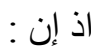

A ثنابت ارينيوس و Ea A يعطي الرسم الناتج من رسم Log 1/T خطا مستقيما بميل مساوي رسي لقيمة ( ) - Ea / 2.303 R ) (12) ، اما قيمة $1 H^{*}$ فتحسب من المعادلة الآتية : $\Delta \mathrm{H}^{*}=\mathrm{Ea}-\mathrm{RT}$ : من المعادلة $\Delta \mathrm{G}^{*}$ $\Delta \mathrm{G}^{*}=-\mathrm{RT} \log \mathrm{V}_{\max }+\mathrm{RT} \ln (\mathrm{KT} / \mathrm{h})$...(11)

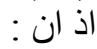

جدول (3):قيم الدوال الثرموديناميكية للحالتين القياسية والانتقالية لارتباط (الالنين-4-نايتروأنلايد) مع

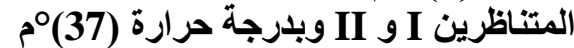

\begin{tabular}{|c|c|c|c|c|c|c|c|}
\hline Isoenzyme & $\begin{array}{c}\Delta \mathrm{H}^{\circ} \\
\mathrm{Kj} \cdot \mathrm{mole}_{1}^{-}\end{array}$ & $\begin{array}{c}\Delta \mathrm{G}^{\circ} \\
\mathrm{Kj} \cdot{ }_{1}^{\text {mole }}\end{array}$ & $\begin{array}{c}\Delta \mathrm{S}^{\circ} \dot{\circ} \\
\mathrm{J}^{-d e g^{-1}} \text { mole }^{-}\end{array}$ & $\begin{array}{c}\Delta \mathrm{H}^{*} \\
\mathrm{Kj} \cdot \mathrm{mole}_{1}^{-}\end{array}$ & $\begin{array}{c}\Delta \mathrm{G}^{*} \\
\mathrm{Kj} \cdot \mathrm{mole}_{1}^{-}\end{array}$ & $\begin{array}{c}\Delta \mathrm{S}^{*} \\
\mathrm{~J}^{*} \mathrm{deg}^{-1} \mathrm{~mole}_{1}^{-}\end{array}$ & $\begin{array}{c}\mathrm{E}_{\mathrm{a}} \\
\mathrm{KJ} \cdot{ }_{1} \mathrm{~mole}^{2}\end{array}$ \\
\hline I & 1.5 & -3.8661 & 4.85 & 29.77 & -4.40 & 110.25 & 125.93 \\
\hline II & 0.33 & -0.463 & 1.06 & 37.98 & -3.88 & 135.07 & 160.29 \\
\hline
\end{tabular}




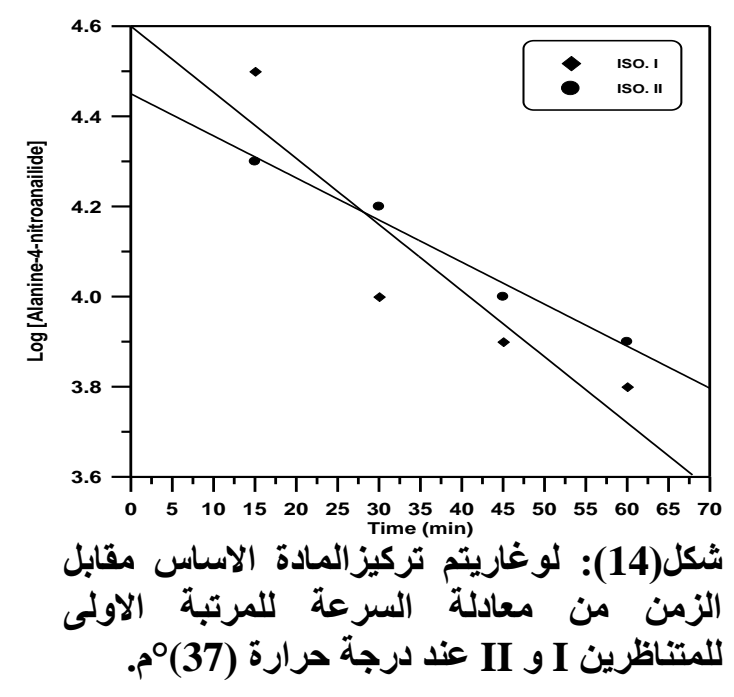

$\mathrm{AAP}+$ Alanine -4- nitroanilide $\rightleftharpoons \mathrm{AAP}$-Alanine -4- nitroanilide

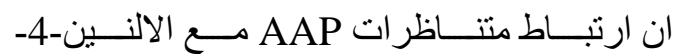
نايتروأنلايد يمكن التعبير عنه بالمعادلة الآتية[19]:

$\mathrm{E}+\mathrm{S} \underset{\mathrm{k}_{-1}}{\stackrel{\mathrm{k}_{1}}{\longrightarrow}} \mathrm{ES} \stackrel{\mathrm{k}_{\mathrm{p}}}{\longrightarrow} \mathrm{P}$

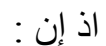

AAP ) ثابت سر عة التفاعل لتكوين المعقد Alanine aminopeptidase ميل الخط المستقفم في معادلة المرتبـة الأولى عند رسم الزمن مقابل فعالية الأنزيم .

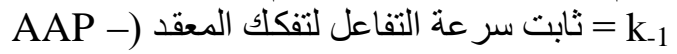
ون (Alanine aminopeptidase ومن خلال الشكل (14) يلاحظ أن قيمة [ S

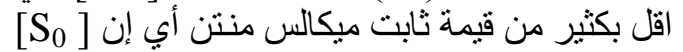

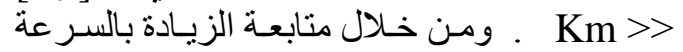

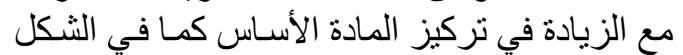

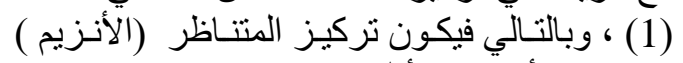

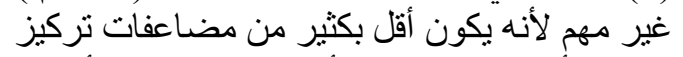

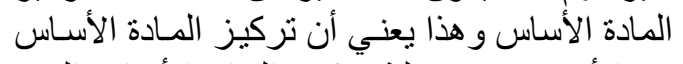

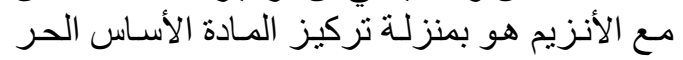

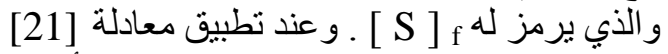
Scatchard للتوازن التر ابطي بين المسادة الأسـاس $\frac{|S|_{b}}{|S|_{f}}=-\frac{1}{K s}\left[\left.S\right|_{b}+\frac{n|E|_{t}}{\mathrm{Ks}} \ldots . . . . . .(17)\right.$

[S ] تمثل تركيز الألنين-4-نايترو أنلايد المرتبط

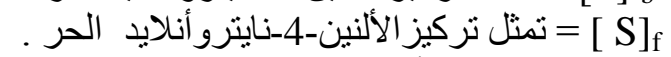
[E] t

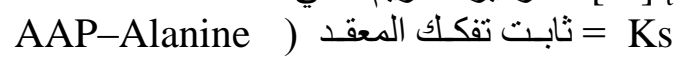
. ( aminopeptidase = ع عدد جزيئات الأرتباط . n
2- حركيات مرتبة التفاعل لمتناظرات انزيم الالنين

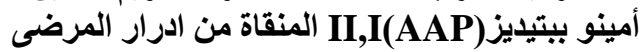
المصابين بسرطان الجهاز البولي:

يوضح الثكل(13)العلاقة بين زمن التفاعل وفعالية الانزيم وبدرجة حرارة(137)مه

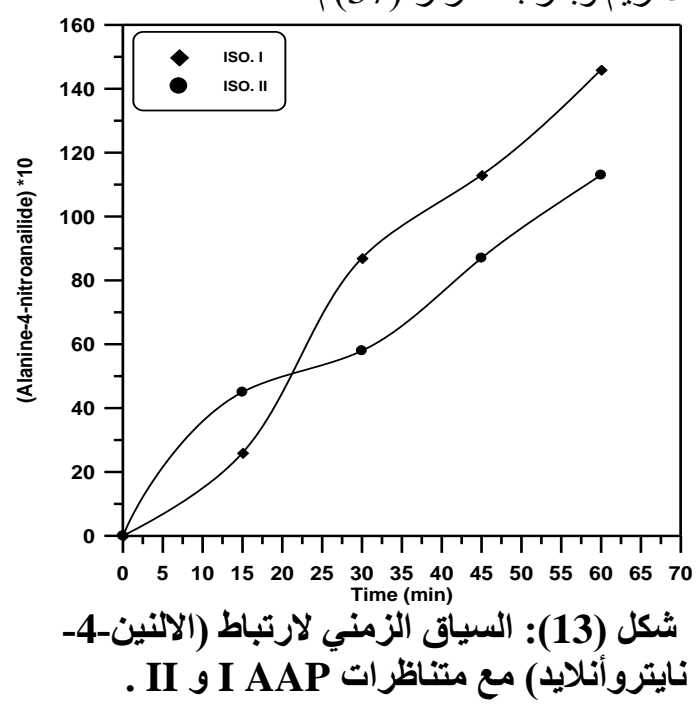

ومن الشكل (1) يلاحظ ان السرعة تتناسب طرديا

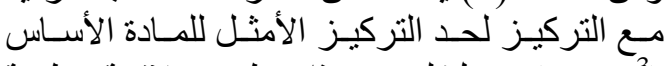

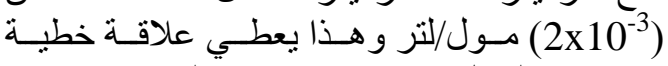

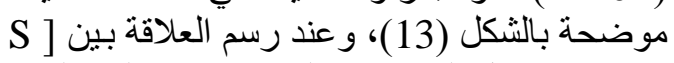

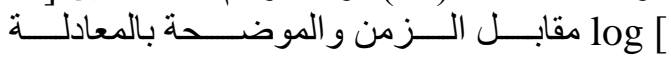

$\log S=\log$ So $-\frac{k \cdot t}{2.303}$

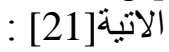

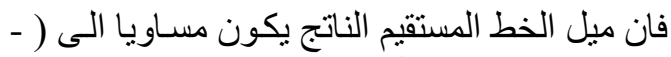

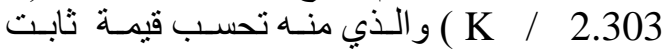

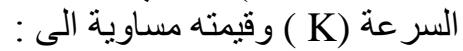

$\mathrm{k}=\frac{\mathrm{Vmax}}{\mathrm{Km}}$

اذ يوضح الثكل (14) قيم الثنابت (k) للمتناظرين و و المساوية 12و 39 دقيقة-1 (II ، I ) وهي تمثنل وحدة الثابت عندما يكون التفاعل مـن الثن المرتبة الأولى . 
و ان العلاقة بين ثابـت التوازن Ka وثابـت التفكلك Ks

$$
\mathrm{Ka}=\frac{1}{\mathrm{~K}_{\mathrm{S}}}
$$

لذا بمكن حسـاب قيمـة ثابت التوازن Ka لذان

AAP-Alanine

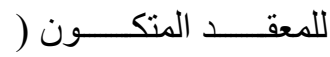

) و الذي يمثل بالمعادلة الآتية

$$
\mathrm{Ka}=\frac{\mathrm{k}_{1}}{\mathrm{k}_{-1}} \ldots \ldots \ldots . . . .(20) \quad \mathrm{Ks}=\frac{\mathrm{k}_{-1}}{\mathrm{k}_{1}}
$$

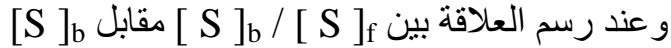

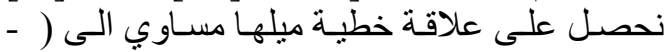

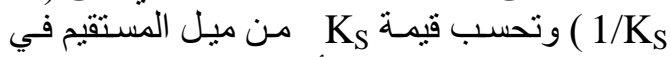

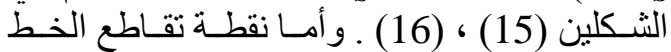

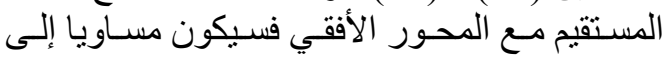

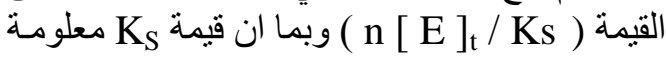

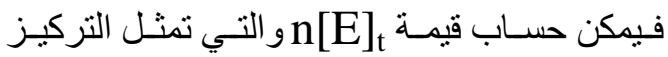

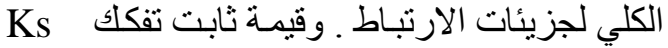

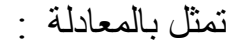

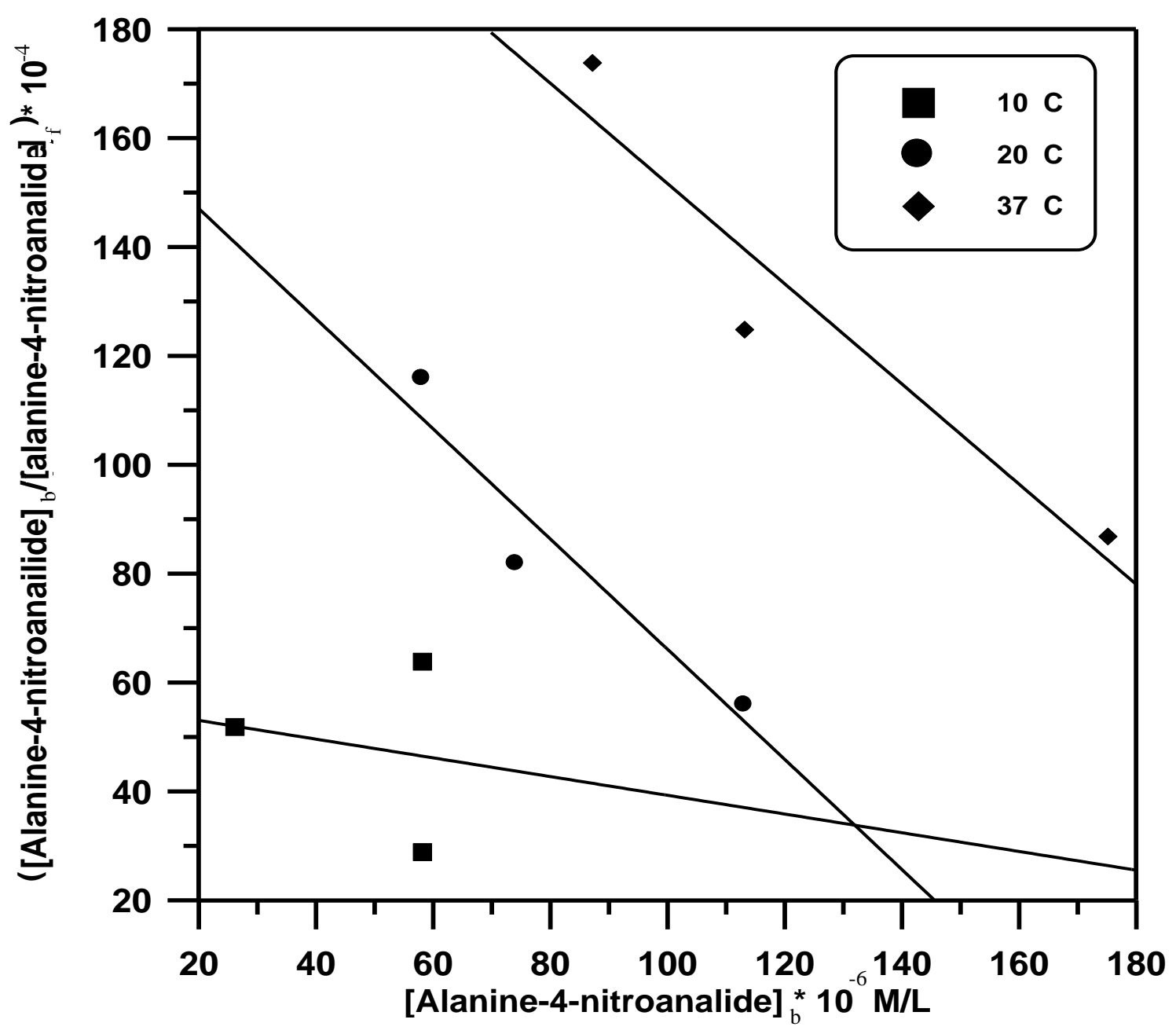

شكل (15) : رسم Scatchard لارتباط المادة الأساس مع المتناظر ( I ) وبدرجات حرارية مختلفة ( , 37 . 


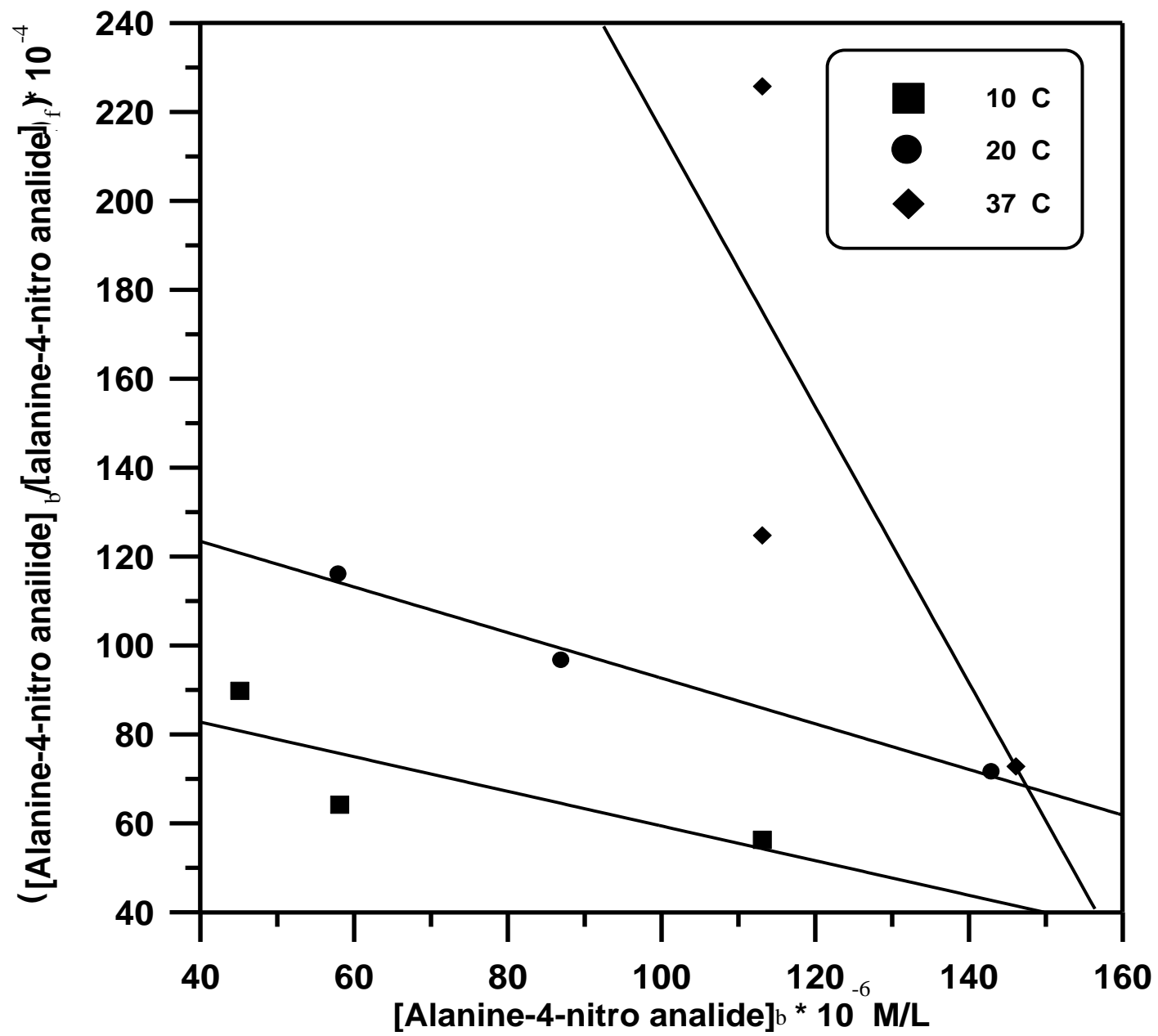

شكل (16): رسـ Scatchard لارتبـاط المـادة الاسـاس (الالنين-4-نايترو أنلايـ) مـع المتنـاظر II حرارية مختلفة (10,10, (37,20,10)م.

الهمال الخطوة المتعاكسة (الخطوة المحددة ل اللسر عة)و دليل ذلك مايأتي: 1- القيم العالية لثابت الاتزان للمتتاظرين (II,I) إذ إن . $\mathrm{K}_{-1}<\mathrm{K}_{+1}$

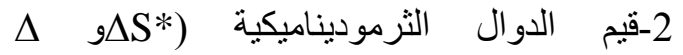
(الجي الجدول(3)مقارنة بقيمها بالحالة

$$
\text { الاساس و المستقرة. }
$$

هذا يعني أنه سيضمن انتقال معظم الجزئيات باتجاه AAP-Alanine-4-(المكوين

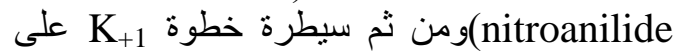

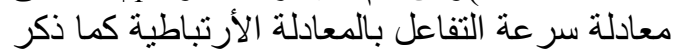

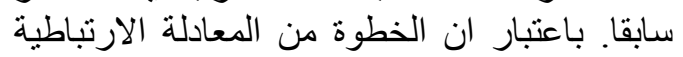

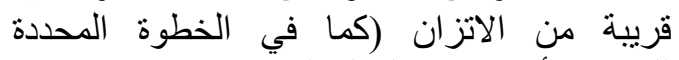

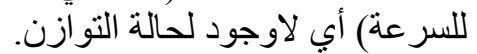

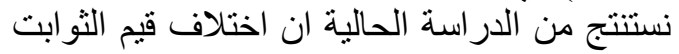

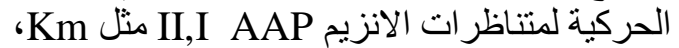
التركيز الامثل للمادة الاساس، الدالة الترائ الحامضية

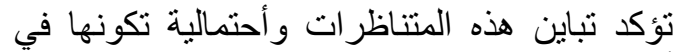

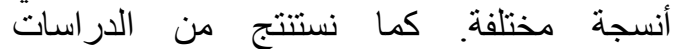
الثرموديناميكية ان القوة اللدافعة للتفاعلات الارتباطية تعتمد على دالة التغينة التغير بالانتروبي
جدول (4): قيم الثوابت الحركيـة لارتبـاط المسادة

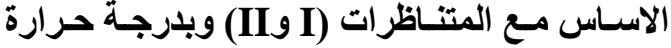
. (37)

\begin{tabular}{|c|c|c|c|c|}
\hline Isoenzyne & $\begin{array}{c}\mathrm{K}_{+1} \\
\mathrm{~mole}^{-1} \\
\mathrm{~min}^{-1}\end{array}$ & $\begin{array}{c}\mathrm{K}_{-1} \\
\times 10^{-3} \\
\mathrm{~min}^{-1}\end{array}$ & $\begin{array}{c}\mathrm{K}_{\mathrm{a}}= \\
\left(\mathrm{K}_{+1} / \mathrm{K}_{-1}\right) \\
\mathrm{mole}^{-1}\end{array}$ & $\begin{array}{c}\mathrm{Ks}=\left(\mathrm{K}_{+1} / \mathrm{K}_{-1}\right) \\
\times 10^{-3} \mathrm{~mole}^{-1}\end{array}$ \\
\hline I & 12 & 2.66 & 4.5 & 0.22 \\
\hline II & 3.9 & 3.25 & 1.2 & 0.83 \\
\hline
\end{tabular}

ومن متابعة قيم الثوابت في الجدول رقم(4) يتضح

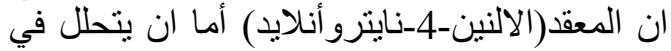

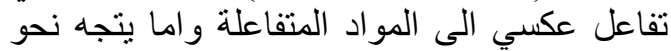

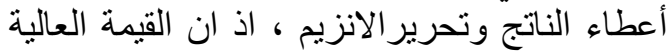
لثابت الأتزان Ka

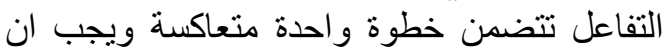
تكون متبوعة بخطوة بطيئة نسبيا والتي بدورة هانيا تكون متبوعة بخطوة أكثر سرعة. ومن نبئ الميكن 
intesthne mucosa-purification and characteristics, Z Med Lab Diagn.,21(1);9-17.

9. Muhammed,A. Maurice,P. Jan, F.C. and Glatz,B. 2003, Do tissue damage biomarkers used to assess machine-perfused NHBD kidneys predict long -term renal function post-transplant? Clinica Chimica Acta, 338,pp33-43.

10. Sidorowicz,W. Hsia, W.C., Zownir, O.M.and Behal, F.J.1980,Multiple molecular forms of human alanine aminopeptidase :immunochemical

propertiess,Clin.Chim.Acta.,107;24 5-256.

11. Lopponen,S.L and Makinen ,M. 1985, Amicrotiter plate assay for $\mathrm{N}$-acetyl- $\beta$-D-glucos-aminidase using an fluorogenic substrate, J.Ana .Biochem., 148;50-53.

12. AL-Akabie, T.U..2006, Biochemical studies of Alanine aminopeptidase isoenzymes partially purified from patients urine having urinary tract cancer, Ph.D. thesis, College of Education, Tikrit university.

13. Jung,K. and Scholz.,D. 1980 An optimized assay of alanine aminopeptdase activity in urine, Clin. Chem.,26(9);1251- 1254.

14. Mattenheimer,H. Frolk,W.H and Simane,Z.1986, Identifiction of inhibitors of urinary alanine aminopepthdase,

Clin.Chim.Acta., 160;129;135.

15. Kao,Y.J. Starnes W.L and Behal, F.J. 1987,Human kidney alanine aminopeptidase: physical and kinetic properties of a sialic acid containing glycoprotein. Biochem., 17(15);2990-4.

16. Tsushima,H. Sumi,H. Ikeda,R. Yoshida,E. Mihara,H and Havu,V. 1990,Low molecular weight alanine aminopeptidase of human serum: separation and some
( مماتدل على أهمية التأثيرات الكارهة للماء في تكوين المعقدات الناتجة.

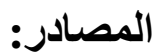

1. Manisha,Jh. Jie,L. Rebecca,B. Ashish, M. and Barton, G.2007,Urinary tract disease and bladder cancer risk: acase - control study, Cancer Causes andControl.,18(8); 839-845.

2. Myrhoj, T. Andersen,M.B. and Bernstein, I. 2008, Screening for urinary tract cancer with urine cytology in Lynch syndrome and familial colorectal cancer, Familial Cancer, 7(4); 303-307.

3. Furukawa, J. Miyake, H. Hara, I andTakenaka, A, 2007, Upper urinary tract recurrence following radical cystectomy for bladder cancer, Intl. J. Uro, 14(6);496-499.

4. Takayanagi, A. Masumori, N. Takahashi,A and Takagi, Y. 2012. Upper urinary tract recurrence after radical cystectomy for bladder cancer: Incidence and risk factor, Intl J.Uro, 19(3); 229-233.

5. Michael, S. 2008, An automated assay of urinary alanine aminopeptidase activity, Clin Chem Lab Med, 46, 537-40

6. Birgit,H. Lehmann,A. and Gero, K,2000, Diagnostic value of urinary alanine aminopeptidase and $\mathrm{N}$-acetyl- $\beta-\mathrm{D}$ glucosaminidase in comparison to $\alpha 1$ microglobulin as a marker in evaluating tubular dysfunction in glomerulonephritis patients, Clinica Chimica Acta, 297, 93-102.

7. Tsushima,H. Sumi,,H. Ikeda,R. Yoshida, E. Mihara, H.and Hopsuhaw, V.1990.Low molecular weight alanine aminopeptidase of human serum :separation and some characterhstics.Biomed Biochim Acta.,49(5);38-327.

8. Hutter, H.J. Graving hoff, Jand I. Bohme, 1980,Alanine aminopeptidase in human small 
19. Segel " Biochemical Calculation " Culifornia. 1976.

20. Donald, V, 2008. Principles of Biochemistry,(3ed John WileyandSons, Inc).pp11-17.

21. Tinco,S. Wang, $P$ "Physical Chemistry .,4th,U.S.A ,198.2002. characteristics. Biomed. Biochin. Acta., 49(5);327-38.

17. Wielend.G. and Molinof P. 1980, Thermodynamic of agonist and antagonist interaction with mammalian beta adrenergic receptors. Mol. Pharmacol, 18; 341-347.

18. Atkins.P.W .,"Physical Chemistry $.8^{\text {th }}$. Oxford .Univ,press Oxford 2006.

\title{
Kinetic and thermodynamic Studies Of Alanine Aminopeptidase(AAP) Isoenzymes I,II Partially Purified From Patient's Urine With Urinary Tract Cancer
}

\section{Taghreed U.Al-Akabie*}

*College of Eudction- Ibn Al-Haytham, Baghdad university

\begin{abstract}
The activity of Alanine aminopeptidase( AAP ) was measured in the urine of healthy and urinary tract cancer patients, the results showed higher activity of (AAP) in patients compared to healthy. AAP was Purified from the urine of healthy and patients with urinary tract cancer by dialysis and gel filtration (Sephadex $G-50$ ) and two isoenzymes of (AAP) were separated from urine by using ion-exchang resin (DEAE - Sephadex A - 50) in previous study.

The kinetics studies showed that both isoenzymes I and II obeyed Michaelis - Menton equation . with optimal concentration of alanine-4-nitroanilide as substrate for isoenzymes I and II which was $\left(2 \times 10^{-3} \mathrm{~mol} / \mathrm{L}\right)$. The two isoenzymes obeyed Arrhenius equation up two $37^{\circ} \mathrm{C}$ and their $\mathrm{E}_{\mathrm{a}}$ and $\mathrm{Q}_{10}$ constants were determined . The binding of alanine-4-nitroanilide by two isoenzymes I, II were studied and the kinetic constant $\left(\mathrm{k}_{+1}, \mathrm{k}_{-1}, \mathrm{~K}_{\mathrm{a}}, \mathrm{K}_{\mathrm{s}}\right)$ were indicated that the reaction was first order at $37^{\circ} \mathrm{C}$. Thermodynamic parameters of the standard state $\left(\Delta \mathrm{G}^{\circ}, \Delta \mathrm{H}^{\circ}, \Delta \mathrm{S}^{\circ}\right)$ and the transition state ( $\Delta \mathrm{G}^{*}, \Delta \mathrm{H}^{*}, \Delta \mathrm{S}^{*}$ ) were determined by using Vant Hoff and Arrhenius equations.
\end{abstract}

